\title{
Contra la textolatría. Las motivaciones creativas en los testimonios de Arguedas, Alegría, Churata e Izquierdo Ríos
}

\author{
Dorian EsPezúa SAlmón \\ Universidad Nacional Mayor de San Marcos \\ dorian_espezua@hotmail.com

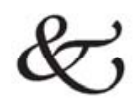

\section{Resumen}

Entre agosto y octubre de 1966, Godofredo Morote Gamboa organizó una serie de conferencias en las que poetas, dramaturgos y novelistas dieron testimonio personal sobre aquello que los motivaba a escribir sus textos. De esa serie de conferencias que se dieron en la Universidad Nacional Federico Villarreal, el profesor Morote seleccionó y publicó cuatro que corresponden a cuatro autores clásicos de la narrativa peruana. En efecto, las cuatro conferencias versan sobre las "motivaciones" que llevaron a José María Arguedas, Ciro Alegría, Gamaliel Churata (Arturo Peralta) y Francisco Izquierdo Ríos a escribir sus imprescindibles y respectivos textos. Estas cuatro conferencias espontáneas tienen un alto valor documental, ya que sirven para cotejar los modos de "contar" una misma experiencia o vivencia en diferentes escenarios y ante distintos públicos. Una consecuencia inevitable que se desprende de lo anterior es que también estas conferencias sirven para corregir opiniones críticas que carecieron de esta fuente testimonial.

Palabras claves: Testimonio, experiencia vital, Arguedas, Churata, Alegría, Izquierdo Ríos.

\begin{abstract}
From some of our most representative poets', dramatists' and novelists' testimonial accounts on what motivated them to write (University Federico Villarreal, 1996), four of our narrative classics were selected and edited by G. Morote Gamboa. The edition of these spontaneous gatherings offer an opportunity to analyze the authors' ways to tell similar experiences in different scenarios and before different audiences, and help critics to profit from first-hand valuable sources.

Key words: Testimonies, Vital experiencies, Arguedas, Churata, Alegría, Izquierdo Ríos.
\end{abstract}


1. Los textos reunidos y subrepticiamente publicados por el profesor Godofredo Morote Gamboa son importantes porque permiten explicar los textos a partir de los contextos de producción. No son ni serán útiles para aquellos que consideran que el texto debe defenderse solo y que, finalmente, no hay ninguna relación entre el autor y el texto. Estas cuatro conferencias que en realidad son cuatro testimonios casi confesionales se oponen a la textolatría que desvincula el texto de sus referentes y, peor, aún, de su instancia productora. A pesar del enorme desarrollo que han alcanzado disciplinas como la narratología, la semiótica o el análisis del discurso, no debemos descartar de plano, por teorías y metodologías de moda, los aportes del biografismo o el historicismo dado que también contribuyen a aclarar el múltiple sentido textual. Además, las teorías psicoanalíticas, la línea bajtiniana, la sociocrítica, las teorías marxistas, la pragmática, la teoría del efecto estético, los estudios culturales, los estudios postcoloniales y hasta los estudios de género nos demuestran que es necesario tomar en cuenta los contextos para explicar el texto. Las cuatro conferencias reunidas por el profesor Morote Gamboa son, en buena cuenta, testimonios de vida y testimonios sobre las "motivaciones" que llevaron a estos cuatro narradores a escribir. En ese sentido, son paratextos imprescindibles para aclarar el significado y el sentido de los textos de estos excelentes narradores.

2. José María Arguedas se confiesa con el auditorio y testimonia algunos tópicos recurrentes manifestados, por ejemplo, en el Primer encuentro de narradores peruanos realizado en Arequipa en 1965. Me refiero a lo que cuenta sobre su infancia "desventuradamente feliz"; a lo que dice sobre el maltrato cruel de su madrasta y sobre todo de su perverso hermanastro; a sus descripciones sobre las corridas de toros en San Juan de Lucanas y a la impresión que le causó cuando tenía 7 u 8 años; a la nostalgia con la que habla sobre su amistad con el burro Azulejo y sobre su lugar con los indios en la cocina; a la revelación de un trauma que lo marcó para siempre que se explicita en la frase: "No vales ni lo que comes"; a su declarada admiración por el poder de los indios de Puquio y San Juan de Lucanas capaces de construir la carretera de 140 $\mathrm{Km}$. que une Puquio con Nazca en 28 días a pesar del menosprecio "auténtico" de los huiracochas que pueden ser llamando también jalas, o 
sea, seres calatos y vacíos que no tienen nada; al extraordinario apunte sobre su pariente Manuel María Guillén quien creía que los indios no tenían alma y era el sujeto más indigno de ser católico a pesar de que se arrodillaba y persignaba cada vez que pasaba delante de un templo; al tono traumático con que cuenta cómo Manuel María Guillén destruyó el acueducto y el molino de piedra que eran "la obra maestra de mi vida"; al relato de cómo se tronchó la mano con el trapiche de moler caña y de cómo estuvo a punto de morir si no fuera por un brujo curandero que lo salvó de la muerte en la hacienda Carqueti; a su narración sobre el pique, el peor castigo de los indios dado que "es un animal que se mete en la carne de la gente y forma allí un nido que es una especie de bolsita y cuando son muchas las bolsas se juntan unas a otras y forman allí unos colgajos. El sexo, especialmente de los chanchos, estaba lleno de estos colgajos, pero también el de los niños" (Morote 1989: 20) ; a lo narrado sobre el flagelo de un indio amarrado en un pisonay, porque se había guardado seis plátanos debajo del poncho, y a cómo, después, Arguedas, que sentía total empatía con el indio, lo acompañó en silencio hasta que se despidieron con un abrazo; al reto que significó para él el colegio San Luis Gonzaga de Ica donde demostró que la gente de la sierra no es inferior ni superior a la gente de la costa.

Es interesante el testimonio de Arguedas sobre cómo llegó a Lima y se integró a la universidad donde sus compañeros vieron que él les traía "algo distinto" que los limeños no conocían. Este es el testimonio de un migrante que conflictivamente conecta dos mundos con todos los problemas que ello implica. Además, Arguedas da testimonio de la mentalidad de una época:

Cuando yo llegué a Lima hacia 1929 la juventud tenía un horizonte limpio del cual recogíamos una fe inquebrantable. Parecía que en muy pocos años se iba a instalar en el mundo un régimen justo, que iba a triunfar el socialismo, que ya no faltaba casi nada, que estábamos para alcanzar las puertas del cielo. La revista Amauta se distribuía en todo el país, era una cosa increíble. [ ] Por otro lado, si había discrepancias entre los apristas y comunistas, en determinados aspectos doctrinarios, no lo había en cuanto a la seguridad de que la revolución estaba allí, a las puertas. Entonces mi generación fue quizás la más afortunada de este siglo y del Perú. Entonces la fe que yo había recogido de la entraña más íntima del pueblo indígena, de los mestizos, de mi propia afirmación constante a lo largo de mi educación que fue muy irregular, fue confirmada, fue 
cimentada con una doctrina y por la seguridad en un mundo justo en el cual cada quien tuviera la oportunidad de contribuir con lo mejor en la sociedad. (Morote 1989: 23-24)

La cita anterior puede cotejarse con el discurso "No soy un aculturado" que Arguedas pronunció cuando recibió el premio Inca Garcilaso de la Vega en 1968, donde afirma que fue leyendo a Mariátegui y la teoría socialista que encontró un "orden permanente en las cosas", pero que esto no mató en él lo mágico. No es sorprendente, por lo que conocemos de las entrevistas que concedió y los testimonios que dio, que Arguedas declare que sus "motivaciones" están en las "experiencias especialísimas" que tuvo en la infancia y adolescencia y en su fe adulta de que un futuro mejor es posible: "Desde entonces, jóvenes, nunca más he perdido la fe en el ser humano; les quiero decir esto porque a través de todo lo que he escrito, no he hecho más que expresar estas impresiones de la infancia y adolescencia" (morote 1989: 22). ¿Hasta qué punto se puede y se debe usar la vida de Arguedas para explicar sus novelas? ¿Cuál es el límite entre el testimonio y la novela? ¿Cuáles son las ventajas y desventajas de explicar la narrativa arguediana a partir de su vida? Los actuales estudios arguedianos está muy preocupados por responder a estas preguntas.

Hay, sin embargo, en el testimonio de Arguedas dos tópicos que quiero rescatar. El primero se refiere al origen real de los personajes y acontecimientos que ha novelado; y el segundo a un cambio de opinión respecto de la apreciación de la narrativa de Oswaldo Reynoso. Con relación al primer tópico, en el discurso de Arguedas se aclara el origen o la "motivación" real de Demetrio Rendón Willka, uno de los personajes prototípicos de la narrativa arguediana que aparece (re)presentado en Todas las sangres. En efecto, lo que dice Arguedas entra en contradicción con lo que, al respecto, ha escrito Rodrigo Montoya en su artículo "Yawar fiesta: una lectura antropológica" (1980). En efecto, a pesar de que Rodrigo Montoya destaca la utilidad de las novelas como fuentes de conocimiento por su valor testimonial, en la cita que reproducimos a continuación hay un dato que entra en contradicción con lo manifestado por Arguedas:

Testimonios de una época, las novelas le sirven a los estudiosos de la realidad social como fuente de conocimiento, pero también como fuente 
de hallazgos que pueden servirnos para orientar nuestros trabajos, para abrirnos los ojos sobre temas, problemas y relaciones que tienen que ver directamente con la estructura profunda de la sociedad. El novelista intuye las tensiones sociales e imagina situaciones límite para sugerir uno o varios modos de solución de esas tensiones. Descubre, igualmente, la importancia de los individuos que encarnan fuerzas sociales y les da vida en la novela. Demetrio Rendón Will[k]a, el personaje extraordinario de Todas las sangres, surgió a partir de un caso real, el obrero De la Cruz, en las minas de San Juan de Lucanas. Su condición de obrero y rebelde quechua dieron a Arguedas los elementos necesarios para crear el personaje y llevarlo hasta la situación límite de ser portavoz de una gran transformación por venir. (Montoya 1980:56)

¿De dónde sacó el dato Rodrigo Montoya? ¿Cuál es el sustento que le permite afirmar que Demetrio Rendón Willka surgió a partir del caso real del obrero De la Cruz, en las minas de San Juan de Lucanas? No tenemos el dato ni la fuente, pero le damos el beneficio de la duda. Arguedas, en cambio, nos da otra versión en la conferencia pronunciada en la Universidad Nacional Federico Villarreal en 1966:

\footnotetext{
La historia de este personaje es en gran parte auténtica. Un indio apellidado Kokchi se atrevió a matricular a su hijo en la escuelita primaria que había en San Juan de Lucanas, donde yo he estudiado las primeras letras. El indio era grandazo, tendría unos 14 ó 15 años, e iba a aprender las primeras letras, iba muy bien equipado: su bolsita de tocuyo especial para el pizarrín, su marquito de madera como antiguamente se usaba y otra bolsa para su mote y su cancha. Lo hostilizaron de tal manera los otros chicos que este muchacho era un verdadero mártir en la escuela; uno de ellos, un día llegó al extremo de arrancarle la pizarra, tirarla al suelo y destrozarla con los pies. Entonces el cholo no pudo más y le mandó un sopapo al sujeto que lo bañó en sangre. Al día siguiente, delante de todos los alumnos hicieron cargar a este indio por un varayoc, le bajaron el pantalón y lo flagelaron y después de flagelarlo le dijeron que no volviera más. Este fue el primer indio que yo vi en una escuela oficial. (Morote 1989: 15-16)
}

Es muy interesante el hecho de que Arguedas reconociera que el mundo que experimentó y vivió era muy distinto al mundo actual y también distinto al de su padre y su madrastra. Esto nos sirve para aclarar que el referente de la narrativa arguediana no corresponde con el mundo "actual" como lo creyeron los científicos sociales y los críticos literarios en la Mesa Redonda sobre Todas las sangres que se realizó en el Instituto de Estudios Peruanos en 1965. Además, Arguedas era 
consciente que en el Perú que él vivió no había un tiempo homogéneo. Los tiempos, las mentalidades, los desarrollos, las sociedades obedecen más bien a lógicas heterogéneas por lo que es difícil hacer corresponder la realidad y el tiempo de un espacio con la realidad y el tiempo de otro espacio. Arguedas es consciente de que el Perú no es una nación imaginada como una unidad, sino un conjunto de nacionalidades reales en permanente conflicto y desigualdad.

Fíjense ustedes cuánto ha cambiado nuestro país. En ese mundo en que yo me movía se pensaba de las cosas de muy distinto modo a lo que en el mundo actual. Se creía firmemente que había un picaflor que volaba y que llegaba hasta el sol y que volvía y que cuando volvía del sol lucía más bellamente que antes de haber hecho el viaje. Se creía que el río era un ser protector con el cual se podía conversar y al cual se le podía pedir cosas buenas; que la montaña también era un dios protector; que luchaban entre ellos; que los pájaros cantaban para un dios y no solamente para regocijarse ellos; que el bailonjo era un mensajero de otro mundo; que la chirrirrinca siempre aparecía cuando el hombre iba a morir. Todo ese mundo en el que yo crecí era muy distinto del mundo en el cual se movía mi padre y mi madrastra. (Morote 1989: 16)

El otro tópico que me interesa comentar tiene que ver con lo que Arguedas opina sobre la literatura de la generación posterior a la suya. Declara su admiración por Mario Vargas Llosa y lo califica de "novelista genial" aunque le reclama que en La ciudad y los perros haya presentado una imagen muy amarga y escéptica del mundo y de la gente. A Vargas Llosa -dice Arguedas- le falta la fe en que los terribles males de nuestro país van a ser superados. Dice de pasada que, en las obras de Julio Ramón Ribeyro, por ejemplo, hay amargura. Sin embargo, hay una opinión sorprendente y lapidaria sobre la obra de Oswaldo Reynoso: "otro testimonio tan atroz es la obra de Oswaldo Reynoso, no sé cómo calificarla. ¿Qué nos ofrece Oswaldo Reynoso? Este escritor que se proclama marxista y leninista, ¿qué es lo que nos ofrece Lima? Una porquería” (Morote 1989: 25). Según Arguedas, hay un estado de incertidumbre en la generación posterior a la suya por la pérdida de la fe en el Perú que se contrasta con:

Las obras de mi generación son obras terribles, es un cuadro terrible que se ofrece del Perú, pero, al mismo tiempo, cargado de fe, de una fuerza que promete construir, desarrollarse hasta alcanzar una sociedad no solamente justa, sino con una faz propia, con una voz que sea distinta 
de las voces de los otros países. Bueno, yo creo que el secreto está en una idea muy precisa que se las quiero transmitir: el odio. Nosotros hemos vivido impulsados por el odio, pero sin amargura; impulsados por la esperanza. La mezcla del odio y la esperanza han hecho caminar a la humanidad. El odio con la amargura han creado la esterilidad, la destrucción que es suicidio (Morote 1989: 25).

La intervención de José María Arguedas "confesional y confidencial” es calificada por el mismo como una conversación. Arguedas cita la competencia de canto entre dos indios que se muestra en Todas las sangres y termina con una frase contundente. "Esa gente no duda, sabe adónde va y yo sé adónde voy” (Morote 1989: 26). El proyecto arguediano como su motivación inicial es incuestionable.

3. Ciro Alegría da "una charla tan familiar y personal" en la que explica que sus motivaciones están asociadas a la necesidad de expresarse libremente, de hablar alto y de comunicar lo que siente. Luego afirma que: "El escritor es, casi siempre, directa o indirectamente autobiográfico; o sea que, por lo general, trata de temas que le han ocurrido y que ha visto o en alguna forma lo han afectado durante su vida" (Morote 1989: 30). Alegría también desarrolla esta idea en el testimonio que ofrece en el Primer encuentro de narradores peruanos de 1965. Es curiosa la coincidencia con Arguedas por cuanto ambos tratan de testimoniar sus respectivas vivencias y experiencias personales. Alegría afirma que "la vida de un escritor influye en sus obras". Sin embargo, no descuida la influencia del entorno de modo que a las motivaciones personales e individuales le agrega las motivaciones colectivas y sociales. Para Alegría, una de las características de la literatura latinoamericana es su indesligable compromiso social. Además, considera que una de las tareas que la crítica debe cumplir para profundizar en sus obras es "estudiar que me ha pasado, por qué he escrito asî". En efecto, Alegría cree que la vida del escritor es central, pero sin descuidar su "capacidad literaria"; son importantes también "las influencias que reciba" y el "estudio que haya hecho". Así, reconoce la influencia de los periódicos que leía su padre con un retraso de 15 días y de la biblioteca paterna donde, por ejemplo, leyó los libros de Raimondi; reconoce también la influencia de sus lecturas (Cervantes, Dickens, Balzac, Dostoievski, Manzoni, Palma). 
Las motivaciones de Alegría lo llevaron a escribir cuando estaba en cuarto de secundaria en el "periodiquito" de su colegio y, posteriormente, en el diario El Norte que dirigía Antenor Orrego. Bien se puede decir que el periodismo le brindó la práctica escritural para emprender la tarea de escribir novelas.

Si Arguedas vivió al lado de los indios, Alegría vivió del lado de los hacendados. La identificación de Alegría con los indios es una clara muestra de lo que podría llamarse, parafraseando a Efraín Kristal, una visión hacendada de los indios. Alegría aclara cómo es posible que habiendo pertenecido a la clase de los hacendados haya escrito sobre los indios. La respuesta está también en su experiencia vital marcada por la desigualdad social y en la figura modélica de su padre, quien era partidario de la revolución francesa y "tenía ideas no propias del medio donde estaba”. Alegría creció con la conciencia de la diferencia de las clases sociales a pesar de que fue testigo de cómo su padre - "una fuente de historia de comunidades"- trataba a los indios de modo diferente que los otros hacendados. El padre de Alegría, según su testimonio, que trataba a los indios como ciudadanos, rompió la costumbre colonial de que no montaran caballos, anuló el trabajo gratuito y protegió a aquellos que se amotinaron y sublevaron contra los hacendados. Estos son los casos de los indios Gaspar y Pancho.

Muchas de las motivaciones o fuentes de las novelas de Ciro Alegría hay que encontrarlas en las narraciones orales (no necesariamente de mitos o leyendas) que escuchó. Ahí están, por ejemplo, las historias que le contó un campesino llamado Manuel Baca, que un día apareció en la hacienda Marcabal Grande con "una llaga tropical que le estaba destruyendo el brazo”. Según Alegría, navegar por el río Marañón, conocer la vida de los balseros y, sobre todo, escuchar las historias de Manuel Baca, que era un narrador nato como muchos campesinos contadores de cuentos, fueron las motivaciones de La serpiente de oro. Esto es corroborado en el artículo "Novela de mis novelas" (1938) donde Alegría menciona al indio Manuel Baca como fuente de los relatos que sirvieron de base para la escritura de su novela.

Este Manuel Baca era un gran narrador, narrador popular, maestro de la narración pienso que era. La mayoría de los que están en esta novela los he oído a Manuel Baca. A veces no se trataba de cuentos fantásticos, ni 
de cuentos folklóricos, sino relatos de sucesos de la vida. Por ejemplo, el episodio de la escalera en las chorreras de los balseros. Eso me lo contó Manuel; desde luego yo conozco el río y lo he navegado, pero cuando yo era muy muchacho; y ningún tiempo quería pasar en esas chorreras. Tal cosa es tarea mayor que la que pueden hacer balseros muy veteranos. Manuel, además de saber tanta historia, era un maestro de la narración, era un maestro de lo que ahora se llama suspenso. Recordando cómo decía sus historias, me ha llamado la atención que éste fuera una especie de cuentista, de novelista, siempre mantenía el interés del oyente hasta que terminaba la historia. (Morote 1989: 35-36)

La gran sequía que experimentó en Marcabal cuando era niño y vio la tierra seca, los árboles deshojados, los animales muertos rodeados por gallinazos; las historias que le contó sus abuela Juana respecto de otras sequías; su recuerdo de la noche que oyó aullar a unos perros en Chile cuando estaba en un sanatorio; y la terapia de la escritura fueron las motivaciones para que escribiera Los perros hambrientos.

Me parece imprescindible la motivación de la principal novela que se ha escrito en el Perú. En efecto, el origen de su tercera novela está en un capítulo de Los perros hambrientos que tituló El mundo es ancho y ajeno. Luego, ese capítulo se hizo una novela con el título Un pequeño lugar en el mundo "que es precisamente el título que ahora tiene". Después de la concepción de la idea, Alegría comenzó la tarea de acumular "el material de recuerdos y de imaginación”, le sumó a esto su anhelo de justicia para luego componer y escribir la novela en "unos meses nomás". La siguiente cita es reveladora, por cuanto aclara varios elementos pretextuales que la crítica debe corroborar y tener en cuenta para estudiar $E l$ mundo es ancho y ajeno.

Sería bueno decirles que, por ejemplo, en el mundo es ancho y ajeno hay algunos personajes reales, novelizados, como el Fiero Vásquez, pues éste fue un bandolero que existió. A este bandolero mi padre lo conoció. Lo que le pasó a comienzos según lo cuento allí, en la novela, es rigurosamente cierto. Cuando mi abuelo vino como diputado, el Fiero Vásquez se fue a su casa y lo volvieron a atacar y se salió otra vez por los cerros y se metió de nuevo en la vida de las comunidades. Esto no me consta, mejor dicho ni siquiera lo he podido verificar por segunda persona. Pero, por ello, no deja de ser cierto que la forma de su muerte es un hecho copiado de la realidad: esa cabeza que aparece que aparece en un matorral de zarzas y que nadie sabe cómo ha llegado a parar allá. Para mí, como novelista, habría sido muy fácil encontrarle una solución 
a este episodio tan curioso, y meter cualquier historia; pero no lo hice porque, en ese caso, la realidad me pareció tan novelesca o más que cualquier invención. El hecho era bastante demostrativo, de acuerdo con la vida azarosa, impetuosa del Fiero Vásquez; así que lo dejé, y eso es absolutamente cierto. Hay otras cosas que no lo son, otras que las he inventado. El personaje Rosendo Maqui, por ejemplo, nunca existió, sin embargo como todo personaje novelesco que adquiere vida, la gente, el público, el lector piensa que es el que existió. Seguramente creen que lo saqué de la realidad y por eso la gente lo encuentra en la realidad (Morote 1989: 45-46).

El Fiero Vásquez y Rosendo Maqui son con toda seguridad los personajes más emblemáticos de la narrativa de Alegría. Alegría reitera en esta conferencia lo que había expuesto un año antes en el encuentro de escritores de Arequipa sobre el origen de sus personajes. Sobre la factura de Rosendo Maqui y su especial recepción se puede consultar el artículo "Mi personaje Rosendo Maqui" (1963). En la cita anterior hay varios tópicos muy interesantes. El hecho de que los personajes tienen una doble fuente: la realidad y la invención de modo que se crea un mundo compuesto de lo fáctico y lo contrafáctico; la idea de que la experiencia incluye también al testigo de oídas que no necesariamente es un testigo presencial; la intención de no manipular la historia factual dado que la realidad puede ser más novelesca que la ficción; el efecto que un personaje ficcional bien elaborado puede causar en los lectores hasta el punto de considerarlo real. Alegría cuenta cómo el diario Expreso envió a Hugo Neira a Pacará para que hiciera un informe sobre si había encontrado o no a Rosendo Maqui. Este personaje se había convertido en un ícono, en un símbolo, de modo que pasó de existir en la ficción a existir en el mundo real: "En todo caso, yo he querido hacer de Rosendo Maqui un arquetipo del alcalde indio, del alcalde de la comunidad" (Morote 1989: 46). Más adelante, Alegría responde a la crítica que sostiene que su novela idealiza al indio y que, por lo tanto, deja de ser realista. Es curioso que una crítica similar se le haya hecho a José María Arguedas y Todas las sangres: "El reproche que se le hace a mi novela por gente que no la ha leído bien es que yo he idealizado la vida india. Esto no es cierto, ahí se encuentran indios de toda laya: indios ignorantes, indios malos, indios medio idiotas, por ejemplo Valerio" (Morote 1989: 47). Alegría (re)presenta la complejidad de la sociedad peruana y, en 
esto, se parece mucho a Arguedas. No obstante, la invención del personaje no alude a la invención sobre la nada. En la cita que reproducimos a continuación, se demuestra que la ficción tiene su origen en la realidad experimentada por el novelista.

También habría otra motivación directamente más especial, relacionada con las comunidades. Cuando yo estaba chico, en esa región donde nací, las comunidades indígenas estaban pasando por una razzia de parte de los hacendados. Es la zona norteña, seguramente, la que más ha sufrido y donde la comunidad indígena es muy débil. En ese sentido yo tuve una experiencia temprana en la persona de un indio llamado Gaspar, que se fue a refugiar, como muchos otros, en la hacienda Marcabal. Lo que pasaba con Gaspar y una comunidad que se llamaba Bambamarca, que queda más allá del Marañón, era muy parecido a lo que cuento en El mundo es ancho y ajeno. Esta comunidad había sido despojada de gran parte de sus tierras por un juicio de linderos. Un día el hacendado se fue al pueblecito, cuando estaban celebrando la feria. Entonces Gaspar encabezó un motín. A un hombre tranquilo, serio, sobrio, como era Gaspar, qué indignación le daría el desalojo que se amotinó con los otros indios e hizo una sublevación contra el hacendado. Este se refugió en una casa; pero como ahí lo acosaron los sublevados y se la quemaron, salió echando tiros, mató a varios indios y logró escapar junto con sus caporales. Cuando vino la averiguación y el juicio consiguiente, Gaspar de una sola carrera llegó a Marcabal. Como mi padre tenía influencia, lo mismo que mi abuelo, allí se quedó hasta que terminó el juicio. A mí siempre me llamó la atención este indio que era analfabeto sabio, quien sabe en él había un antecedente de Rosendo Maqui, aunque no era lo mismo. Rosendo Maqui es un personaje que yo lo he recompuesto (Morote 1989: 34-35).

Si la cita anterior está relacionada con el hecho de quién pudo haber dado origen a Rosendo Maqui, la siguiente cita nos revela cuál fue el lugar en el que Alegría se basó para escribir su novela: "En Cajabamba me conecté con la vida del pueblo. Esta era una ciudad de 6000 u 8000 habitantes en esos años. En ella vi gran parte de las cosas que cuento en El mundo es ancho y ajeno. Por ejemplo en materia electoral, esas elecciones que se hacían a balazos" (Morote 1989: 39). Nada es inventado, 
todo es reelaborado; nada de lo narrado por Alegría ha salido de la nada $\mathrm{y}$ todo tiene un origen vivencial.

Por otro lado, Alegría confiesa la influencia que ejerció en él su contacto con la naturaleza en Marcabal como en Quilca y su contacto con "el pueblo indio". En efecto, Alegría no pretende hablar por los indios ni suplantar su voz; sí pretende hablar de los indios con los cuales se identifica. El indigenismo de Alegría, como él mismo lo dice, trata fundamentalmente de problemas sociales con una marcada visión antropológica. En la siguiente cita, se nota claramente la visión occidental del hijo de los hacendados que se "junta" con el hijo de la cocinera que es el otro por quien siente empatía.

\begin{abstract}
En Marcabal, ya mi conocimiento de la naturaleza se amplió con la hacienda más grande. Iba por el campo y ahí tuve un amigo que era el hijo de la cocinera, un tipo indio que se llamaba Rogelio. Esta fue mi primera impresión directa del pueblo indio. Este muchachito que era de mi edad y con el cual jugaba por el campo, le reconocía, así chico como estaba, una formidable capacidad para conocer la naturaleza, la típica de los indios, lo mismo que una vista y un oído magníficos. Él oía el trote de los caballos a la distancia, así no los viera. Este muchachito, además, era muy bueno, porque es por naturaleza bueno hasta que se deforma a palos. Este indiecito fue mi amigo, lo mismo que los otros muchachitos de la hacienda que vivían cerca. Las casas de los peones están muy lejos de la casa hacienda. Así conocí al pueblo indio, muy cerca y desde muy niño (Morote 1989: 37).
\end{abstract}

Cuando Ciro Alegría tenía siete años fue alumno, en Trujillo, de César Vallejo en el colegio San Juan. Alegría evoca la imagen de César Vallejo en el artículo "El César Vallejo que yo conocí" (1944). La impresión que le causó su maestro fue tremenda, porque el poeta peruano "era un indio, un cholo vestido a la moderna que era profesor y solía escribir versos audaces y polémicos" (Morote 1989: 37-38), con una fama de loco y chiflado en toda la ciudad. Alegría dice que Vallejo "era realmente un hombre muy triste, con una tristeza fundamental; hombre tierno y desde luego de una sensibilidad muy fina" (Morote 1989: 38). Repetidamente, Alegría remarca que Vallejo era un indio o un cholo dado que "Físicamente se parecía a un peón de la hacienda que se llamaba Cayetano Luna y a quien le decíamos Cayo" (Morote 1989: 38). Ciro Alegría confiesa algo difícil de creer por lo sorprendente. En efecto, manifiesta que con siete años leía los poemas de Vallejo. 
En fin, yo, como alumno de Vallejo, posiblemente también experimenté esta influencia porque leía sus versos, ya que en mi casa tenía una tía que era escritora y que nunca publicó, pero sí le gustaba escribir y leer, y era muy partidaria de este poeta. Quizá por eso, desde chico comencé a leer estos poemas de Vallejo, tan tremendos. Su lectura con ayuda del diccionario, me impresionó mucho también aunque no entendía bien. Sería exagerado decir que los entendía; pero algunos, sí, y me parecía bien. Desde luego yo no pensaba en ser escritor, no sabía todavía lo que iba a ser; pero posiblemente me influyó esta temprana experiencia de un profesor primario que era poeta, un gran poeta (Morote 1989: 38).

En otra parte de su intervención, Ciro Alegría confiesa no recordar bien cuál fue la experiencia inicial que originó su deseo de escribir, ni en qué tiempo fue. Ello nos demostraría que sus experiencias fueron madurando y se fueron sedimentando hasta el momento en que era ya imposible no expresarlas. Alegría manifiesta que hay dos circunstancias muy especiales vinculadas al nacimiento de su vocación como escritor. La primera, cuando leyendo un cuento le dijo a su madre que quería ser escritor y, la segunda, cuando yéndose a caballo a un lugar llamado Colpa en la hacienda Marcabal Grande, escuchó cantar a las torcazas mientras iba cayendo el sol. En ese momento, dice Alegría, sintió el deseo de expresar esa emoción, pero no lo hizo sino hasta años después en El mundo es ancho y ajeno. Alegría nos habla de Idilio andino, una novelita romántica muy mala que perdió, pero que significó asumir el reto de escribir una novela. En 1930 intentó escribir una novela sobre Huanchaco y fue ganado por la política que le hizo experimentar la cárcel, la persecución, el riesgo de morir y el destierro a Chile, donde se decidió a escribir en serio un cuento titulado La Balsa que, posteriormente, se convirtió en la novela que ganó el concurso convocado por la editorial Nacimiento que lo sacó del anonimato.

No hubo tiempo para que Alegría concretizara su proyecto de ampliar el panorama de sus novelas. Nunca apareció su novela sobre el imperio de los incas que tenía como motivación cotejar la información que proporcionan los cronistas y consolidar una cultura nacional en la que puedan integrarse todas las nacionalidades. Sólo añadiré, para terminar, que Nécker Salazar Mejía (2009) tiene una tesis imprescindible sobre Ciro Alegría que espero pueda publicar pronto. Creo que después 
de Tomás Escajadillo, él es el que más conoce la obra y la vida de Ciro Alegría.

4. En el breve y desgarrador testimonio de Francisco Izquierdo Ríos se puede notar una continuidad respecto de lo expresado en el Primer encuentro de narradores peruanos donde había declarado que se encontraba en el momento de su madurez intelectual. En efecto, en sus intervenciones en el encuentro de Arequipa están prácticamente todos los tópicos que repetirá un año después en la Universidad Nacional Federico Villarreal. En ambos momentos, Izquierdo declara que hay correspondencia entre su vida y su obra de modo que la realidad es la fuente de su creación. En efecto, esta es su propuesta dado que el escritor -dice Izquierdo- es el producto del medio en que ha nacido y vivido. Para Izquierdo hay tres elementos que configuran al escritor. Primero están las impresiones que causan la naturaleza, el hombre, la comunidad, las creencias, las costumbres y los problemas en la formación del escritor. Estás impresiones se dan básicamente en la infancia donde se encuentra "un vasto mundo de motivos para la creación artística". El segundo elemento está relacionado con las lecturas del escritor que contribuyen a formar su personalidad. El tercer elemento está expresado en la siguiente cita:

Pero ante todo y sobre todo -aunque parezca una perogrullada lo que voy a expresar- el artista (escritor, poeta, músico, pintor) debe tener aptitud de tal. Sin aptitud no puede ser artista auténtico. Dicha cualidad, por supuesto, va ampliándose y perfeccionándose con el tiempo, en el crisol de la experiencia y de la cultura. (Morote 1989: 51)

No es sorprendente que a ninguno de los cuatro escritores le haya parecido relevante referirse a las técnicas narrativas. La técnica es para ellos un asunto que depende enteramente de lo que se quiere narrar. La técnica para Arguedas, Churata, Alegría e Izquierdo tienen que ver con la búsqueda de un idioma que exprese el "alma" indígena del Perú. Para los cuatro el asunto de la técnica pasa por tener un proyecto ético y estético que trascienda el mero aprendizaje de estrategias narrativas. La técnica está asociada a la búsqueda de la originalidad y no a las preocupaciones por los alardes verbales. Los cuatro reconocen que es indispensable el conocimiento de las técnicas narrativas, pero creen que 
es peligroso su utilización exagerada porque se pierde la espontaneidad y lo que Izquierdo llama la "chispa" de la creación. No es casual entonces que Izquierdo le preste más atención a las experiencias personales, a las lecturas de formación y a la aptitud. En una de sus intervenciones en el encuentro de narradores de Arequipa, Izquierdo sintetiza bien su propuesta de los tres elementos que configuran al escritor:

Estimo por conveniente que, en primer lugar, debemos considerar la aptitud, la calidad innata de escritor; necesidad de escribir como la de comer y dormir, según expresión, si no me equivoco de Rainer María Rilke. Esta aptitud debe ser cultivada para una mejor expresión, a través del tiempo, por medio de lecturas y experiencias de la vida (PENP, 1986: 175).

$\mathrm{Si}$ estos tres elementos que forman parte de la personalidad y del mundo peculiar del escritor son expresados sin traición, entonces se produce la originalidad. En caso contrario se cae en el artificio y en la falsedad. Para Izquierdo "el escritor genuino y consciente de su misión no comete ese error, se da íntegro y sinceramente en su obra, ofreciendo por cierto, un sello inconfundible de originalidad" (Morote 1989: 52). La originalidad, sin embargo, es indesligable de la libertad absoluta. En esa línea, la obra de arte contiene "mensajes" humanos, sociales o artísticos que obedecen a la extracción y formación del escritor. Para Izquierdo hay obras que sólo exaltan la naturaleza y los sentimientos (Isaacs, Shakespeare, Garcilaso, Gutiérrez de Cetina, Manrique, Kayam, Cervantes, Lope de Vega, García Lorca, Neruda, Quiroga o Alegría), hay otras que alientan "el ideal de contribuir a mejorar la humanidad exponiendo sus defectos y presentando soluciones" (Rabelais, Cervantes, Voltaire, Pushkín, Gogol, Turgueniev, Korolenko, Gorki, Chejov, Sholojov, Alegría, Arguedas, Palma). Esta lista de autores es interesante por cuanto nos informa acerca de cuáles son los libros que formaron la personalidad del escritor y por consiguiente sobre la intertextualidad de su obra.

Respecto de su origen sociocultural, Izquierdo testimoniará, con algunas variantes, lo mismo que dijo en el encuentro de Arequipa. Me refiero a su origen modesto, pueblerino, a su nacimiento en Saposoa, en la cuenca del Huallaga, donde vivió parte de su infancia y entró en contacto con su abuela campesina "toda superstición" y con su tía ciega 
"verdadera enciclopedia de cuentos populares de la selva". No obstante, lo más sorprendente es su convivencia con los indígenas amazónicos: "Más tarde viví cierto tiempo en plena selva virgen con un grupo de indios semicivilizados, lo cual es para mí una de las más prodigiosas vivencias, que todavía no he recogido en libro" Morote 1989: 54). No puedo dejar de anotar aquí que la visión de Izquierdo es también antropológica y por lo tanto indigenista. Luego, cuando tenía siete años, se trasladó con su familia a Moyobamba donde concluyó sus estudios primarios y secundarios. Es muy interesante el relato que hace de su primer viaje a la remota Lima cuando tenía dieciséis años. Este viaje duraba más de un mes. Su ansia de lectura era ya incontenible. Comenzó a escribir muy temprano. Esta ruta representa muy bien el tránsito de los escritores provincianos que, partiendo de comarcas orales con carencias bibliográficas, van en búsqueda de una locación en la ciudad letrada. Es la ruta de la búsqueda del libro y del sistema letrado. En efecto, Izquierdo con sus artículos paisajísticos, los mitos, las leyendas y los cuentos populares de nuestra amazonia que publicó en La Crónica y El Comercio logra integrarse a la ciudad letrada.

Es muy interesante el periplo docente de Izquierdo. Graduado como profesor en el Instituto Pedagógico Nacional. Expulsado del mismo por razones de ideas, aunque nuevamente incorporado gracias a las enérgicas gestiones de sus compañeros de estudios. Recibido de maestro retornó a su tierra y trabajó sólo un año hasta que lo enviaron preso a Satipo. Lo liberaron en Chachapoyas y se quedó en la Cordillera Oriental por unos cuantos años ejerciendo de profesor de escuela. Izquierdo se queja de que siempre fue removido de su cargo y de que anduvo de un lugar a otro. Esto le sirvió para conocer costa, sierra y selva. Cuando Izquierdo da la conferencia es Jefe de Publicaciones de la Casa de la cultura del Perú. Toda la vida -dice Izquierdo- soportó abusos, relegamientos e incomprensiones. Como prueba, Izquierdo cuenta cómo después de obtener en concurso público la plaza de Inspector de Educación en una provincia serrana, fue trasladado violentamente a una provincia de la selva que quedaba a un abismo de distancia. En ese entonces su mujer se encontraba embarazada y no tuvieron otra salida que viajar por tierra a la selva para no perder el trabajo. Izquierdo tenía la intención de dejar a su familia en Chachapoyas, pero en el camino nacieron sus 
mellizos que poco después murieron y a los que tuvo que enterrar bajo unos nopales "en medio de la noche sin estrellas". Izquierdo anuncia que este relato y otros aparecerán en su novela inédita Mateo Paiva, el maestro, que debía publicar después. El hecho de que Izquierdo narrara este acontecimiento en el encuentro de narradores de Arequipa, en la Universidad Nacional Federico Villarreal y que decidiera escribir una novela evidencia la presencia de un trauma permanente.

Izquierdo comparte la idea de la función social de la literatura, y de la influencia de la literatura en la sociedad y viceversa. Hay que reconocerle a Francisco Izquierdo Ríos como a Arturo D. Hernández el mérito de haber incorporado al hombre y la cultura de la Amazonía a la literatura peruana. Tradicionalmente se ha hablado del Perú profundo refiriéndose sólo a la sierra del Perú y nos hemos olvidado de la mayor parte de nuestro territorio (72\%). Además, en la narrativa de Izquierdo el paisaje y la naturaleza son motivos estéticos y literarios de modo que la descripción se convierte en la principal técnica narrativa. Finalmente, la literatura para Izquierdo es una herramienta fundamental para construir la identidad regional y nacional.

5. Es sorprendente que Gamaliel Churata, tal vez el narrador peruano más original e importante, no haya sido invitado al Primer encuentro de narradores peruanos que se dio en Arequipa en 1965. Churata murió en Lima el mismo año que Arguedas, pero mientras el segundo era enterrado multitudinariamente como un reconocimiento justo a su aporte a la cultura, el primero era enterrado casi en privado y sin haber gozado del reconocimiento justo que también merecía. Eso prueba que Churata no fue entendido ni por la crítica literaria de su época ni por el público lector. ¿A qué se debe esto? Churata nos lo explica tanto en la conferencia que dio en la Universidad Nacional Federico Villarreal como en la conferencia que pronunció en Puno el 30 de enero de 1965 (publicada en 1971) tres meses después de su retorno de La Paz. Arturo Peralta cambia su nombre a Gamaliel Churata. No debemos hablar de un seudónimo, sino de un nombre que remplaza a otro nombre. Esto nos indica un proceso de identificación que se complementa a la identidad. Churata quiere ser un indio y lo consigue así no haya nacido en Puno y así no haya dominado completamente una lengua nativa. El proceso 
de su identificación corresponde al proceso evolutivo de su proyecto estético. Gamaliel Churata no es ya Arturo Peralta.

Hubiera sido importante que se transcriba la presentación que Godofredo Morote Gamboa hizo de Gamaliel Churata porque este último quedó abrumado por la misma y porque continuamente Churata concuerda con el discurso de su presentador. Churata, que había asistido acompañado del coronel Choquehuanca, descendiente directo de Huayna Cápac y de José Domingo Choquehuanca, confiesa ser un hombre que "ha estructurado su conciencia al amor de las morfologías telúricas de la tierra" y, a pesar de haber nacido en Arequipa, dice ser un hijo del Titicaca, un puneño que en su literatura trata de representar la naturaleza del Altiplano. Tan puneño es que nos habla su historia, de sus mujeres, del Collasuyo y del famoso Hatuncollur, del matriarcado en Tiahunaco, de Manco Cápac y Mama Ocllo; tan puneño es que también él tiene el "espíritu de rebeldía constante" y "la mentalidad superior" que según Churata caracteriza a todo puneño. Tan puneño es que en "El pez de oro o la dialéctica del realismo psíquico, alfabeto del incognoscible" (1965) declara que El pez de oro, su brillante y único libro publicado, está labrado con materiales puneños.

A diferencia de los otros testimonios, el de Churata más bien propone un proyecto ético, estético e ideológico que trasciende las motivaciones personales. En efecto, Churata asume una motivación colectiva relacionada con la tarea de construir una literatura que nos represente. En eso es fiel a las convicciones que lo llevaron a dirigir el Boletín Titikaka y el Grupo Orkopata. Churata busca la "identidad" de la literatura peruana y latinoamericana en las "raíces telúricas" de nuestra naturaleza y cree que nuestra literatura sólo tendrá futuro si es que rescata el ethos representado por las raíces culturales, fundamentalmente de aquellas que pertenecen a nuestra matriz cultural. Churata dice algo contundente: "El Perú no es una más de las repúblicas americanas, es la república americana por excelencia” (Morote 1989: 59). De este modo se resalta el hecho de que es el Perú el país donde se originaron las raíces culturales de la matriz cultural indoamericana y el que posee la tradición histórica, arqueológica, antropológica y linguíística más importante que debe capitalizarse para fortalecer una identidad cultural y literaria. El proyecto ético, estético, social, político 
y literario de Churata se fundamenta en la "conciencia de lo nacional". Para Churata no hay conciencia nacional sin raíces culturales. Nuestro peruanismo y americanismo como lo sustenta bien en $E l$ pez de oro debe estar fundamentado en las culturas prehispánicas a las que tenemos que agregar o insertar las culturas foráneas. Churata es por lo tanto uno de los iniciadores del proyecto estético-literario descolonizador. Haber nacido en esta tierra, según Churata, nos impone la tarea de articularnos con nuestras raíces y de reconciliarnos con nuestra historia.

Para Churata el escritor -y en esto sigue a Nietzsche- "escribe con sangre cuando vive de la sangre de su naturaleza". La naturaleza para Churata tiene que ver con el ser enraizado en un tiempo y en un espacio. Es solo ese ser el que nos permite ser originales en nuestra expresión. Así, el ser americano pasa por reconocernos como indios o no ser americanos, pasa por enraizarnos como frutos en la tierra o renunciar al proyecto estético, pasa por sobrevivir y renacer de nuestra "naturaleza palingenésica eterna"o desaparecer diluidos por lo que no somos. Churata es un convencido de que las culturas prehispánicas no han desaparecido porque aún están presentes sus raíces y porque el ahayu-watan de los pueblos no muere ni puede morir. En consecuencia, el árbol no ha muerto, sino más bien está latente, es una potencialidad que debemos explotar. Churata exhorta a que reguemos el árbol, a que lo hagamos crecer fuerte y frondoso. No se trata, sin embargo, de buscar esencialismos. El hecho de que Churata diga: "Nosotros somos indios o admitamos que no somos de América" (Morote 1989: 64) no quiere decir que busquemos una pureza étnica puesto que -y lo dice él- se puede ser indio y tener los ojos azules. "La naturaleza étnica de la nacionalidad no está en el color de la piel, está en el movimiento del alma, está en el impulso de la voluntad creadora" (Morote 1989: 64). Se trata de partir de nuestras raíces culturales, de nuestros genes para hacernos diferentes o de desaparecer aplastados por la colonización.

Gamaliel Churata, en la conferencia que pronunció en el Cine Puno de 1965, propone el "categorema" ahayu-watan que él traduce como "el alma amarra", clave para entender su filosofía. El ayahu-watan son los genes inmortales de un pueblo y de sus hombres que son invulnerables a la acción de todo agente letal. El ahayu-watan es la naturaleza histórica de los individuos, es la inmortalidad de la semilla, la inmortalidad 
del alma y de los muertos que nunca mueren porque son los vivos de hoy. El ahayu-watan es el alma del sujeto, de la lengua y de la cultura que permanentemente se reencarna en el presente. El Ahayu-watan es la Necrademia donde los muertos no sólo viven, sino que viven en nosotros y nos determinan, es la semilla humana que nunca desaparecerá, es el rizoma cultural.

Churata pasa después a explicar el único libro que publicó en vida y curiosamente lo describe como un libro que está compuesto de siete libros y como una especie de antología. Hay, sin embargo, un dato que es más sorprendente: "El pez de oro, en gran medida, comenzó a ser escrito en la escuela primaria" cuando aún vivía el ambiente del aula. Es entonces una "enciclopedia", una "obra gigantesca" que tomo un largo tiempo de maduración, de organización, de estructuración que posiblemente se haya gestado por influencia de su maestro José Antonio Encinas y que se materializó cuando Churata era ya un adulto. Recordemos que Churata abandona la escolaridad siendo un púber y se convierte en un autodidacta y en un líder adolescente de La Tea y líder juvenil del Grupo Orkopata. En uno de esos libros -dice Churata- estudia la naturaleza de la coca y se opone a aquellos que consideran que constituye un vicio, un tóxico, causante del atraso del pueblo indio. En cambio para Churata la coca es un vitalizador de la naturaleza, "el cirineo que ha sostenido a este pueblo abatido por la esclavitud. En otro capítulo de El pez de oro Churata reclama a los intelectuales "la necesidad de vivir en América y no morir en América". En efecto, no se puede ser un hombre comprometido con su pueblo si uno se desentiende de los problemas que atañen a su pueblo; no se debe -si se puede- hablar de América desde una posición enunciadora desvinculada del referente; no se debe -si se puede- usar a América como un pretexto para obtener beneficios académicos o prestigio profesional. "Vivir en América, quiere decir, aceptar el complejo de todas las contradicciones de la naturaleza histórica y sobreponerse a los impactos de la naturaleza que trata de emulsionar en el complejo vital de la sangre americana" (Morote 1989: 60). No se puede vivir América cerrando los ojos a la realidad, viviendo aquí como si no estuvieras aquí, añorando el momento de regresar sin atreverse a regresar, huyendo de sus problemas para que los resuelvan otros, refugiándose en el discurso, desvinculándose del otro cultural, 
renegando de nuestras raíces, arrepintiéndose de haber nacido aquí. Vivir en un lugar es otra manera de vincularse con el ahayu-watan.

Churata dice que su libro es la exaltación de dos símbolos el koriPuma que es el animal-hombre y el kori-Challwa que es el pez de oro que representa al gen humano. Estos dos símbolos se enfrentan para abatir al Wawaku que es la deidad de la pestilencia, la muerte y la esclavitud. Estos símbolos son Apus, cerros que luchan de forma fantástica. Estamos pues frente a una novela que funciona como una alegoría de la supervivencia cultural. "Al escribir la leyenda de los cerros, impone comprender que el hombre no tiene otra forma de salvarse que volver a las raíces animales y hacer de su alma, o sea de su gen, el ideal de la vida. El gen según la embriología moderna, como ustedes saben, está considerado un ser inmortal, los genes no mueren" (Morote 1989: 63). Esta alegoría corresponde exactamente al proyecto estético que propone Churata dado que de lo que se trata es de rescatar los genes que no mueren y de volverlos a la vida. En buena cuenta El pez de oro es una alegoría de la batalla entre la vida y la muerte, pero, más específicamente es la alegoría de la batalla de una cultura cuyos genes y raíces todavía están vivos que se enfrenta a otra que quiere desaparecerlos. Por otro lado, esta alegoría representa la concretización del categorema ahayu-watan propuesto por Churata. Si los genes están vivos entonces los muertos están vivos, si los genes están vivos nuestra cultura está viva, si los genes están vivos, nuestros antepasados prehispánicos están vivos. Esto implica no considerar al individuo egocéntrico sino a la colectividad, a un "conglomerado de conciencias humanas". En efecto, los genes están vivos en todos y para todos.

Churata se muestra de acuerdo con el principio básico expuesto por Morote Gamboa que sostiene que la literatura del Perú es una literatura española porque está escrita en español. Recordemos que en la conferencia de 1965, Churata dijo que: "Idiomáticamente, la literatura del continente es literatura colonial" (Churata 1965: 20). Eso le da pie para introducir el otro componente fundamental en su proyecto ético, estético, político e ideológico, me refiero al componente linguí́stico. En efecto, Churata dice: "La literatura es idioma o no es literatura. Mientras nosotros escribamos en español, tenemos necesariamente que pertenecer a la naturaleza hispánica de la literatura, por más que 
las inquietudes que nos lleven sean una literatura de insurgencia, de revuelta, de levantamiento. En ese caso, literatura no es ya literatura española, pero es literatura de la colonia” (Morote 1989: 61). También en su conferencia de 1965 Churata había reclamado que los americanos teníamos que decidirnos si somos americanos o somos españoles y había planteado la radicalización de nuestra naturaleza. No es correcto llamar a nuestra literatura española, pero si es correcto llamarla literatura de la colonia puesto que no nos hemos independizado del idioma colonizador ni lo hemos modificado al punto de hacerlo nuestro. En consecuencia, y tal como lo hicieron los españoles con el latín, la tarea consiste en construir una lengua híbrida o kuika que exprese nuestra "naturaleza medular". Veamos la siguiente cita:

Ese es el valor de mi libro que no ha sido comprendido, tal vez porque su idioma pretende ser nuevo; pretender ser hibridal, como ha señalado el profesor; pretende establecer la necesidad de crear un idioma propio nuestro si es que no hemos de volver al régimen del runasimi, del quechua que ha sido la lengua general del país, del cual eminentes filólogos europeos del siglo XIX, dijeron que no era un dialecto, sino que era la lengua más rica, más expresiva, más sublime que había concebido el hombre. (Morote 1989: 64)

Obviamente el proyecto linguístico de Churata tiene dos posibilidades de materializarse. La primera no descarta que se desarrolle una escritura en quechua, en aymara o en lenguas amazónicas. Sin embargo, Churata es consciente que este proyecto puede ser utópico, anacrónico y marginador. En consecuencia, propone como algo más viable la construcción de in idioma "kuiko", multilinguie que represente la heterogeneidad cultural del Perú. Voy a citar dos opiniones aparentemente contradictorias que en realidad son complementarias respecto del proyecto linguístico de Churata. Estas citas corresponden a la conferencia que dio en 1965 y que fue publicada en Lima por el Instituto Puneño de Cultura en 1971 con el título Gamaliel Churata. Antología y valoración. Con relación a la primera posibilidad Churata dice:

Lo que en realidad quiere sugerir la hibridación que se manifiesta en mi libro, es que los americanos estamos obligados a restituir como lengua oficial de la República del Tawantinsuyo, el idioma de nuestros padres, los Inkas, y de nuestras madres, las Koyas y Mamakunas, como han hecho los indonesos cuando sacudieron la dominación británica. (Churata 1965: 23) 
La cita anterior nos presenta claramente la primera y prioritaria tarea linguiística propuesta por Churata que corresponde muy bien con la lógica que sostiene que no hay literatura americana porque no hay americanos y porque no hay lengua americana. En la siguiente cita se muestra la segunda posibilidad más real y practicada por el mismo Churata. De lo que se trata es de insertar en el español la raíz quechua-aymara. No puedo dejar de mencionar aquí que el proyecto linguiístico de Churata, como el de Arguedas, no toma como base la lengua nativa. En ambos proyectos el idioma base en el que debemos -si podemos- insertar la lengua nativa es el español. En buena cuenta hay, en ambos proyectos, una subordinación del quechua y el aymara al idioma de Castilla.

\footnotetext{
Queda establecido que El pez de oro es de una literatura que no persigue ciertamente la creación de un idioma, como parece que juzgó algún cimero hombre de letras americano, cuyo nombre no puedo evocar puesto que la versión no llegó a mí directamente; pero sí pretende infundir en el hispano una emotividad idiomática, que en alguna manera nos hable de las raíces de la Runa-Simi, que yo llamo el Kheswa-aymara. (Churata 1965: 24)
}

En otra parte de su intervención Churata rinde homenaje a sus amigos, los miembros de "la generación más brillante de la historia indigenista" que integraron el Grupo Orkopata (son mencionados Alejandro Peralta, Emilio Romero, Enrique Encinas). "Todos estos hombres tenían una sola obsesión: no interpretar al indio, sino expresarlo" (Morote 1989: 65). Efectivamente, El Grupo Orkopata se caracterizó por estar conformado básicamente por mestizos e indios de manera que bien se puede afirmar que su discurso se enmarca bien dentro del discurso indigenista, pero también dentro del discurso indígena que se apoderó de la letra. Churata nos habla de la evolución del indio formado en la escuela Orkopata cuando cuenta su experiencia de haberlos encontrado convertidos en periodistas, en maestros, en escritores, en industriales o en hombres de gran prosperidad. Churata cita al profesor José Portugal quien dice que el Grupo Orkopata fue la universidad de una generación. Agrega Churata que: "Allí, en Orkopata, vivíamos, pensábamos y escribíamos con los indios y en indio" (Morote 1989: 66). Eso explicaría el carácter único de esta vanguardia y también explicaría el por qué no fue comprendido. Quiero resaltar que con esta declaración Churata 
está evidenciando que el proyecto indigenista del Grupo Orkopata era también un proyecto indígena.

\begin{abstract}
De mi libro han dicho que es raro porque no se entiende. iCómo se le va a entenderi ¿Ustedes conciben que se pueda entender un libro cuyo idioma ustedes no conocen? No. Eso es lo que ocurre con este libro. El idioma que utiliza este libro resulta desconocido por los americanos y es que América casi ya no existe. La obra que debe imponerse al régimen de la cultura americana es aquella que partiendo de las universalidades enseñe a los hombres, que el hombre no tiene derecho a poseer una personalidad si niega sus raíces. Y, ¿cuáles son esas raíces del hombre? Las raíces de la tierra. Somos de América o no somos indios o no somos americanos. Esto no quiere decir un enfrentamiento ceñudo o sañudo contra el europeísmo; no quiere decir que debamos rechazar las expresiones de la cultura moderna, que debamos cancelar todas las expresiones de la cultura de occidente. No. Lo que tratamos de hacer entender es que podemos ser muy modernos, pero siendo muy antiguos. (Morote 1989: 66)
\end{abstract}

Esta cita condensa todo el proyecto estético de Gamaliel Churata que trasciende lo que publicó en vida. En efecto, Churata nos informa, al final de su intervención, que su obra consta de dieciocho volúmenes de los que sólo se ha publicado El pez de oro. Churata anuncia la aparición próxima de La resurrección de los muertos, de una colección de poemas donde hace de la poesía un campo de debate filosófico, de un libro de poemas titulado Haylli incásico y de otro que se llama Mayeútica. Hasta donde conocemos toda la obra de Churata está en manos del investigador italiano Ricardo Badini quien es el encargado de hacer que esas obras circulen entre nosotros. Sin embargo, no puede seguir siendo posible que las instituciones encargadas de velar por nuestra cultura no tengan la "visión" de recopilar nuestro patrimonio literario y filosófico que es el capital simbólico para que aquí y desde aquí podamos "producir" conocimientos. No puede seguir siendo posible que nuestro patrimonio cultural, en este caso literario y filosófico, esté en manos privadas y que, por lo tanto, no tengamos la posibilidad de realizar estudios sobre tan valiosa e importante obra.

Finalmente Churata declara estar muy emocionado por haber vuelto a la patria y por haber entrado en contacto con los jóvenes estudiantes y expresa su deseo de que le brinden nuevas oportunidades para que, "en forma muy metódica", explique cómo la literatura puede ser un 
camino revolucionario para rectificar los errores de la historia y para que el Perú se constituya en el "cerebro" del nuevo mundo.

6. En los cuatro testimonios recopilados en este libro se puede, de modo evidente o no, rastrear un proyecto común de literatura nacional, una continuidad que los unifica a pesar de la desarticulación, una sistematicidad a pesar de la contradicción. En efecto, los cuatro escritores indigenistas ocupan una posición intermedia en una sociedad clasista y racista. Son el otro para el mundo "blanco" capitalino y son el otro para el mundo "indígena" y provinciano. Sin estar invitados a ninguna fiesta participan de las dos porque ellos mismos se han invitado. Son escritores puente con la tarea de comunicar las naciones separadas de la oficialidad o más bien con la tarea de insertar el mundo indígena serrano y selvático dentro de la tradición literaria del Perú; son escritores transculturales, híbridos, suprregionalistas, calibanes, heterogéneos, pertenecientes más a la comarca oral que a la ciudad letrada a la que finalmente se integraron. Estoy seguro que los que los caracteriza es proponer una modernidad otra desde un lugar de enunciación que está evidenciado por la experiencia vital. Su vida es su lugar de enunciación.

\section{Referencias bibliográficas}

ALEGRÍA, Ciro (1938): “Novela de mis novelas”. Sphinx № 3. Lima: pp. 105-110.

ALEGRÍA, Ciro (1944): "El César Vallejo que yo conocí". Cuadernos americanos № 6. México: pp. 175-191.

ALEGRÍA, Ciro (1963): “Mi personaje Rosendo Maqui”. Hierro y futuro. Lima: mayo.

ARGUEDAS, José María (1968): "No soy un aculturado". Palabras en el acto de entrega del Premio Inca Garcilaso de la Vega. Lima.

CHURATA, Gamaliel (1965). "El pez de oro o la dialéctica del realismo psíquico, alfabeto del incognoscible”. En VARIOS AUTORES (1971). Lima: pp. 11-36.

MESA REDONDA SOBRE TODAS LAS SANGRES. 23 de junio de 1965 (1985): Lima: Instituto de Estudios Peruanos. 
MONTOYA, Rodrigo (1980): "Yawar fiesta: una lectura antropológica". Revista de Crítica Literaria Latinoamericana, № 12. Lima: pp. 55-68.

MOROTE GAMBOA, Godofredo (1989): Motivaciones del escritor. Arguedas, Alegría, Izquierdo Ríos, Churata. Lima: Universidad Nacional Federico Villarreal.

PRIMER ENCUENTRO DE NARRADORES PERUANOS (1986): Lima: Latinoamericana Editores.

SALAZAR MEJÍA, Nécker (2009): Ficcionalidad y referencialidad en el mundo es ancho y ajeno. Tesis de Magíster en Literaturas Hispánicas. Lima: Pontificia Universidad Católica del Perú.

VARIOS AUTORES (1971): Gamaliel Churata. Antología y valoración. Lima: Ediciones Instituto Puneño de Cultura. 